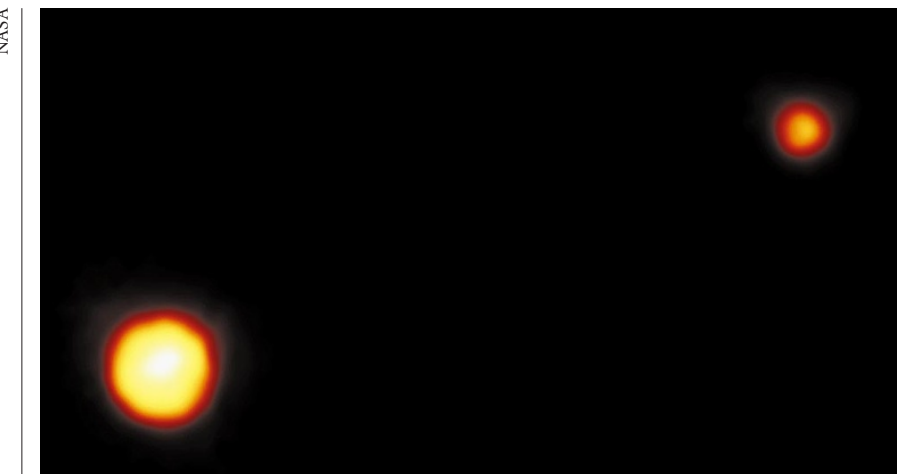

Back on course

NASA has revived its plans to send a probe in 2004 to Pluto, shown here on the bottom left with its moon Charon. The decision could delay any mission to Jupiter's moon Europa until 2010.

\title{
NASA set to move Pluto back up its priority list
}

Tony Reichhardt, Washington

NASA hopes to announce a revival of its plans to send a spacecraft to Pluto in 2004. The turnaround may be confirmed as early as this week.

In a rapid reversal of its September decision to cancel the Pluto mission, the space agency may also allow teams outside its own space research centres to submit plans to design and build the spacecraft.

Ed Weiler, NASA's science chief, halted work on the Pluto-Kuiper Express after the combined cost for it and an associated mis sion to orbit Jupiter's moon Europa grew from $\$ 654$ million to $\$ 1.5$ billion (see Nature 407, 933 and 408, 505; 2000).

That decision, along with other cancelled missions, set alarm bells ringing in the planetary science community. It also forced scientists who advise NASA to state their priorities more clearly.

Michael Drake of the University of Arizona, representing NASA's advisory subcommittee for Solar System exploration, wrote on 27 November to the head of the agency's planetary programme: "It is logical to consider flying [the Pluto mission] first."

Until the Drake letter, Weiler says, planetary scientists had not expressed a clear preference over whether the Pluto or Europa mission should launch first if NASA had to make a choice. "That's the big change," he says.

Weiler has other reasons for sending the Pluto mission back to the head of the queue. Its launch is the more time dependent of the two projects: after December 2004, there will not be another favourable alignment of the planets for a decade, whereas the opportunity to visit Europa comes every 13 months.

Perhaps more importantly, placing an orbiter around Europa has also proved to be an extremely difficult engineering problem, owing to the severe radiation environment at Jupiter and the large amount of energy required to slow a spacecraft into orbit around the moon.
Given these challenges and current budgetary constraints, Weiler says: "If you go to Europa first, you're not launching until 2007 or 2008.

Many scientists outside NASA blame the spiralling costs on the coupling of the Pluto and Europa missions and a NASA directive that the projects must use the same technology. They contend that developing them as separate missions should slash the Pluto mission's price tag.

NASA originally handed both projects to its Jet Propulsion Laboratory (JPL) in Pasadena, without inviting outside proposals. But now, says Weiler: "It's entirely possible that there could be an [announcement of opportunity] in January for a competition to propose a Pluto mission."

Lockheed Martin Astronautics in Denver and the Applied Physics Laboratory at Johns Hopkins University in Baltimore, which operates the current Near Earth Asteroid Rendezvous spacecraft and has taken the lead in several NASA planetary missions, have both been working on ideas for trips to Pluto, and would probably answer any call for proposals.

Drake's letter pointed out that even if a mission to Europa was launched second, it would still return data before the Pluto spacecraft, because of the shorter travel time to Jupiter. But, says Weiler, this turns out to be not quite true, and "is only doable with [additional ] money that we don't have right now."

If the Pluto spacecraft goes in 2004, NASA could not launch the Europa mission until 2010, given the JPL's current plan and cost estimates.

Data would then not come back until 2012 or 2013, compared with 2012 from Pluto. But Weiler hopes that, given more time to develop the technology, the costs of a Europa orbiter could fall.

He expects to make his decision before the end of 2000, and says: "If there's any chance to do Pluto within the available budget, I'm going to find a way to do it."
Japanese genomics company offers shares in sequences

David Cyranoski, Tokyo

A Japanese genomics company has developed a business model in which investors can buy shares in any of the genome sequences the company deciphers.

The idea comes from Takara Shuzo, a brewery company that plans to turn its subsidiary, Dragon Genomics, into Asia's biggest gene-sequencing operation (see Nature 404, 913; 2000).

As sequencing becomes faster and cheaper, the growing number of projects require new ways of financing that do not rely on company or government funding. The investment model for Dragon will be designed to attract investors who are interested in a particular project.

Sequencing projects are planned for the chimpanzee, silkworm, tuna and whale genomes, as well as for certain seaweed and mushroom species thought to have medicinal value.

Shares in the projects should become available during 2001, and profits from licensing agreements following on from the projects' results will be split among investors.

Companies such as the computergames maker Konami have used an investment model based on the funding of individual projects in the past. But Takara believes it is the first company to do this for biotechnology.

It has applied for a 'business method patent' in Japan to cover its model, and is considering similar applications in other countries. "Biotechnology is a very competitive field," explains a Takara representative, "and this is an era for patenting everything and anything."

Takara will set up a separate company to handle the distribution of information to pharmaceutical companies and other interested parties, and to distribute profits to investors. The company will run a web page where investors will be able to monitor the latest status of sequencing, patents and licensing agreements.

Dragon plans to start operations next spring, and to have 45 state-ofthe-art sequencing machines up and running by the summer of 2002. Most of its work will be done on a contract basis for corporations and academic researchers that have "money, but little technological capacity", says Takara's representative. 